\title{
INVESTIGATION OF TRANSPIRATION COOLING PERFORMANCE IN \\ LOX/METHANE LIQUID ROCKET ENGINES
}

Andrea Bucchi ${ }^{*}$, Claudio Bruno $^{\dagger}$, Alessandro Congiunti $^{ \pm}$

\begin{abstract}
A transpiration cooling model using high-pressure, real gas properties has been developed in order to determine methane transpiration cooling performance in the throat region of a highthrust, high-pressure $\mathrm{LOX} / \mathrm{LCH}_{4}$ liquid rocket engine (LRE), such as those being currently investigated in European Union (EU). The model is a series of non linear ordinary differential equations one-dimensional for the conduction-convection of heat between the coolant and the porous material and neglects for simplicity vapour formation. This last assumption occurs, in fact, only with low thermal conductivity materials $\left(k_{\text {wall }}=20 \mathrm{~W} / \mathrm{mK}\right)$ and at low coolant injection temperature $\left(T_{\text {cool_in }}=140 \mathrm{~K}\right)$, these conditions being present only in 3 of the 21 cases examined in the parametric analysis. Only steady-state results are presented; comparisons were not made to test data as experiments to this purpose are still in the planning process. Temperature profiles along the liner wall have been numerically obtained by varying liner porosity $(\varepsilon=15 \% \div 17 \%)$, conductivity $\left(\mathrm{k}_{\mathrm{wall}}=20 \mathrm{~W} / \mathrm{mK}\right.$ and $\left.100 \mathrm{~W} / \mathrm{mK}\right)$ and coolant

\footnotetext{
* Department of Mechanics and Aeronautics, University of Rome "La Sapienza", Rome (ITALY) [bucchi.andrea@libero.it]

$\dagger$ Associate Professor, Department of Mechanics and Aeronautics, University of Rome "La Sapienza", Rome (ITALY), AIAA Associate Fellow [c.bruno@dma.ing.uniroma1.it]

${ }^{ \pm}$Space Propulsion Design Department, Avio S.p.a., Colleferro (Rome) ITALY [alessandro.congiunti@aviogroup.com]
} 
injection temperature $\left(\mathrm{T}_{\text {cool-in }}=140\right.$ and $\left.300 \mathrm{~K}\right)$. Results indicate that profiles of temperatures, pressure and density tend to have sharp gradients near the hot gas porous wall interface. They also show that very low surface temperatures $\left(T_{\max }=500,600\right.$ and $\left.700 \mathrm{~K}\right)$ are possible with a methane transpiration flowrate corresponding to about 5 percent, or less, of that injected in the combustion chamber. The associated specific impulse loss due to the coolant flowrate injected may be at least partially recovered by the increase of turbo-pump efficiency, since pressure losses in the cooling circuit are substantially reduced; furthermore, based on wall temperature predicted, reusability appears potentially higher than that obtainable with other regenerative cooling systems. 


\section{Variables}

a, b coefficients

A area $\left[\mathrm{m}^{2}\right]$

$\mathrm{B}_{0} \quad$ permeability $\left[\mathrm{m}^{2}\right]$

BR blowing ratio

$\mathrm{c}^{*}$ characteristic velocity $[\mathrm{m} / \mathrm{s}]$

$\mathrm{Cp}$ specific heat at constant pressure $\quad[\mathrm{J} / \mathrm{kgK}]$

CR coolant ratio

d characteristic dimension (in $\mathrm{Re}) \quad[\mathrm{m}]$

$\begin{array}{lll}\mathrm{D}_{\mathrm{t}} & \text { throat diameter } & {[\mathrm{m}]}\end{array}$

Dq heat flux error $\quad\left[\mathrm{W} / \mathrm{m}^{2}\right]$

$\mathrm{Dp} \quad$ pressure error (matching condition) $\quad[\mathrm{Pa}][\mathrm{bar}]$

$\mathrm{f}(\mathrm{x}) \quad$ generic function

G generic quantity (error definition)

$\mathrm{G}_{\mathrm{cool}}$ coolant mass flow rate (per unit area) $\quad\left[\mathrm{kg} / \mathrm{m}^{2} \mathrm{~s}\right]$

$\mathrm{h}$ heat transfer coefficient $\quad\left[\mathrm{W} / \mathrm{m}^{2} \mathrm{~K}\right]$

$\mathrm{h}_{\mathrm{v}} \quad$ volumetric heat transfer coefficient $\quad\left[\mathrm{W} / \mathrm{m}^{3} \mathrm{~K}\right]$

$\mathrm{I}_{\mathrm{sp}} \quad$ specific impulse $\quad[\mathrm{s}]$

$\begin{array}{lll}\mathrm{k} \text { thermal conductivity } & {[\mathrm{W} / \mathrm{mK}]}\end{array}$

$\mathrm{K}_{\mathrm{M}}$ molecular weight ratio

$\mathrm{K}_{\mathrm{T}} \quad$ temperature ratio

$\dot{m} \quad$ coolant mass flow rate

$[\mathrm{kg} / \mathrm{s}]$

M Mach number 
$\mathrm{N}$ total number of nodes

$\mathrm{Nu} \quad$ Nusselt number

P pressure

$[\mathrm{Pa}][$ bar $]$

Pr Prandtl number

q heat flux

$\left[\mathrm{W} / \mathrm{m}^{2}\right]$

r recovery factor

$r_{\text {curv }} \quad$ nozzle curvature radius

$[\mathrm{m}]$

$r_{p} \quad$ radius of "spheres" simulating porosity

[m]

Re Reynolds number

$\mathrm{R}_{\mathrm{t}} \quad$ throat radius

$[\mathrm{m}]$

St Stanton number with blowing

$\mathrm{St}_{0} \quad$ Stanton number without blowing

$\mathrm{T} \quad$ temperature

$[\mathrm{K}]$

t wall thickness

$[\mathrm{m}]$

u velocity

$[\mathrm{m} / \mathrm{s}]$

$\mathrm{x}$ coordinate from coolant side to hot gas side of material

$[\mathrm{m}]$

\section{Greek variables}

$\varepsilon \quad$ porosity

$\Phi \quad$ equivalence ratio

$\mu \quad$ dynamic viscosity

$[\mathrm{Pa} \mathrm{s}]$

$\gamma \quad$ heat specific ratio

$\rho \quad$ density

$\left[\mathrm{kg} / \mathrm{m}^{3}\right]$

$\sigma \quad$ defined in Bartz formula

$\omega \quad$ exponent of the viscosity-temperature relation 


\section{Subscripts}

$\begin{array}{ll}\text { ad.wall } & \text { stagnation properties } \\ \text { Bartz } & \text { adiabatic wall (temperature) } \\ \text { CH } & \text { using Bartz formula } \\ \text { comb } & \text { methane } \\ \text { cool, coolant } & \text { coolant } \\ \text { cool_in } & \text { coolant at inlet } \\ \text { cool_out } & \text { coolant at wall exit } \\ \text { cr } & \text { critical conditions } \\ \text { fuel_in } & \text { fuel inlet properties } \\ \text { gas } & \text { bulk hot gas } \\ \text { LOX } & \text { liquid oxygen } \\ \text { max } & \text { maximum value } \\ \text { ox_in } & \text { oxidant inlet properties } \\ \text { porous } & \text { porous material } \\ \text { st } & \text { stoichiometric } \\ \text { wall } & \text { wall material properties } \\ \text { mace hot gas side }\end{array}$

\section{$\underline{\text { Superscripts }}$}

* $\quad$ shielding effect (heat flux) 


\section{INTRODUCTION}

Requirements imposed on the next LRE generation include lower costs (production, insurance, maintenance and operational), more reliability $(0.01 \%$ failure probability per mission: the same risk of losing a military jet-fighter), more durability and better performance (for example, higher thrust-to-weight ratio).

Lower costs may be achieved with a long-life design. Essentially, this means to keep under control the temperature to minimize high thermal and mechanical stresses typical of LRE structures.

Looking at conventional regenerative cooling strategies, new concepts in cooling system are required. A classical example, the Space Shuttle Main Engine (SSME) uses a classical regenerative cooling system; liquid hydrogen flows at high speed in the coolant channels to control heat transfer and cool the engine walls prior to injection. This solution involves high pressure drops and power required by the turbo-pump feed system, resulting in high system weight.

A second problem typical of regenerative cooling is known as thermal ratcheting ${ }^{1}$ : thermal cycling drives large plastic strain in the wall separating coolant from hot gas. With time, the wall becomes thinner, with a high probability of developing cracks.

Among recent concepts to improve cooling are: ${ }^{2}$

Improved Liner Material (ICL)

Elastic Liner (EL)

Microchannel Cooling Structure (MCS)

Thermal Barrier Coating (TBC)

Transpiration Cooling 
Some of these solutions control the damaging effects of high heat transfer by using materials with higher conductivity and larger ultimate strength (ICL), or by deliberately allowing the structure to elastically deform (EL).

The MCS solution reduces the pressure drop in the regenerative cooling system by means of high aspect ratio coolant channels, requiring lower coolant speed, but it is also expensive.

Future reusable LRE systems need a life enhancement by a factor 10 , and most of these approaches cannot realize it. The critical issue is, in fact, the reduction in the ultimate stress of most metallic materials with increasing temperature.

Transpiration Cooling ${ }^{3}$ (active technique) and also TBC (passive technique) address this issue by limiting the effective heat flux acting on the structures. It seems therefore natural to investigate transpiration cooling as a way to improve engine life, since this system allows, in principle, very low wall temperature $(500 \mathrm{~K}-700 \mathrm{~K})$.

Many mathematical models have been developed in the past to describe coolant flow into a porous material. The governing equations in these models require global parameters (such as porosity, permeability, thermal conductivity) to describe porous material behaviour. A critical step in modeling transpiration cooling for propulsive applications (e.g., nozzle cooling) is to estimate the effective heat transfer between the hot gas and the porous wall where a mixing between combustion gas and injected coolant takes place.

The goal of this work is to provide an assessment of the transpiration cooling performance of $\mathrm{LCH}_{4}$ in future large $\mathrm{LRE}$ using $\mathrm{LOX}$ and $\mathrm{LCH}_{4}$ as propellants. Such combinations is, in fact, the object of much interest in (EU) at this time. ${ }^{4}$

An additional incentive to studying transpiration cooling is the issue of reusability, suggesting engine wall temperatures be kept as low as economically possible. Avoiding direct contact between hot products and wall by using transpiration appears, in this context, a potential good strategy. 
Since EU has no prior experience in transpiration cooling, such assessment should provide basic understanding, hopefully quickly pointing out pluses and minuses of this technology. Because of time constraints, the model presented here is topological by simple, while supercritical fluid properties independently developed ${ }^{4}$ have been utilized to better characterize the coolant $\left(\mathrm{LCH}_{4}\right)$.

An efficiency parameter, the coolant ratio (CR), has been introduced to estimate the total fuel mass flow requirement (used as coolant) compared that burned in combustion chamber; CR helps in evaluating the cost advantage (or disadvantage) of a transpiration cooling system capable, in principle, of enhancing engine life.

It is chiefly progress in material technology (especially composite materials) that enables, the development of transpiration cooling. The first attempt tried in a LRE was in the 60's John Chamberlain (at Pratt \& Whitney) ${ }^{5}$ when designing the engine for the future Space Shuttle. Combustion chamber and nozzle throat was formed by many copper wafers stacked together; this system did not embody any porous material, but a form of transpiration cooling was obtained just the same by small involute coolant passages etched into each copper wafer. The most important feature of this design (separate wafers) is shown in this work to be a powerful solution to optimize the transpiration cooling system and at the same time to avoid axial thermal gradient and transverse (oblique) coolant flow. 


\section{TRANSPIRATION COOLING}

In transpiration cooling, the coolant (typically fuel: liquid hydrogen or, as in this study, methane) is injected through a porous material. In this paper we examine the effect of such cooling technique on a porous material constituting the nozzle throat region.

The primary heat exchange takes place between the coolant flow and the porous material: the coolant gets warmer (via conduction-convection heat transfer) and the porous material cooler. A second heat exchange takes place through the thickened boundary layer on the gas side produced by coolant injection, with the coolant film reducing the heat transfer between the porous wall and the hot gas.

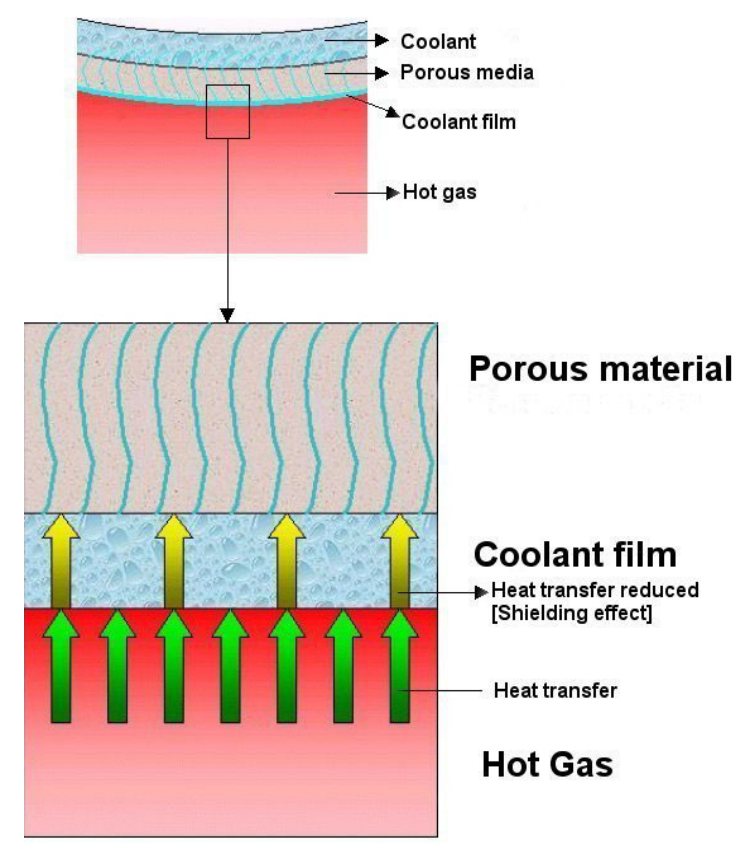

Fig. 1 Transpiration cooling

The critical zone in a rocket engine is the nozzle throat region; in fact, the maximum heat transfer (up to $160 \mathrm{MW} / \mathrm{m}^{2}$ ) ${ }^{6}$ is reached there since the boundary layer has minimum thickness. $^{7}$ 


\section{MATHEMATICAL MODEL}

To enhance engine life the cooling system must limit wall temperature. Since heat transfer is influenced by material porosity and coolant temperature, we must predict the temperature profile through the porous material and what are the factors influencing it most.

The coolant emerging from the pores is injected in the hot gas stream; so one of the physical constraints in modelling transpiration is that the coolant pressure at the pore exit equals the hot gas pressure; hence, also the coolant pressure profile must be predicted.

The mathematical model that follows is the simplest possible (one-dimensional) and includes three ordinary differential equations predicting: porous material temperature $T_{\text {porous }}(x)$, coolant temperature $T_{\text {cool }}(x)$, and coolant pressure $P_{\text {cool }}(x)$ (see nomenclature).

The model equations are:

Energy equation in the porous material

$$
k_{\text {porous }} \frac{d^{2} T_{\text {porous }}}{d x^{2}}=h_{v}\left[T_{\text {porous }}-T_{\text {cool }}\right]
$$

The left hand side (LHS) of (1) is the conduction into the porous material, the right hand side (RHS) describes synthetically the heat transfer between the porous material and the coolant; $x$ is the coordinate along the nozzle radius.

This second order ordinary differential equation needs two boundary conditions (BC):

$$
T_{\text {porous }}(x=0) \rightarrow \text { Assigned }
$$

the wall temperature in contact with coolant is assumed known or imposed, with $\mathrm{x}=0$ determining where the wall is in contact with the liquid coolant. The second $\mathrm{BC}$ imposes the heat transfer transmitted into the porous material (conduction heat transfer) be equal to that transmitted from the hot gas and accounting for the shielding effect of transpiration. 


$$
q^{*}=-\left.k_{\text {porous }} \frac{d T_{\text {porous }}}{d x}\right|_{x=t}
$$

where $\mathrm{x}=\mathrm{t}$ is the station of the wall hot gas interface, " $\mathrm{t}$ " being the wall thickness.

Coolant energy equation

$$
\frac{d T_{\text {cool }}}{d x}=\frac{h_{v}}{G_{\text {cool }} C p_{\text {cool }}}\left[T_{\text {porous }}-T_{\text {cool }}\right]
$$

The RHS of (2) describes synthetically the heat transfer between the porous material and the coolant. Its BC is:

$$
T_{\text {cool }}(x=0) \rightarrow \text { Assigned }
$$

since the coolant injection temperature is assumed known.

Coolant pressure equation: Darcy Law

$$
\frac{d P_{\text {cool }}}{d x}=-\frac{\mu_{\text {cool }} G_{\text {cool }}}{\rho_{\text {cool }} B_{0}}
$$

This ordinary differential equation needs only one BC:

$$
P_{\text {cool }}(x=0) \rightarrow \text { Assigned }
$$

since the coolant pressure injection is typically imposed or known.

\section{Modeling transport terms in the mathematical model}

As a first approximation, the thermal conductivity in the porous material ( $\left.\mathrm{k}_{\text {porous }}\right)$ can be related to the material properties through the porosity $\varepsilon$ (a sort of scaling factor).

$$
k_{\text {porous }}=k_{\text {wall }}(1-\varepsilon)
$$

where $\varepsilon$ is the void fraction in the porous material constituting the nozzle wall. 
The heat transfer coefficient $h_{v}$ is modelled as

$$
h_{v}(T)=\frac{N u k_{c o o l}}{B_{0}}
$$

where $B_{0}$ is the permeability coefficient defined below. $\mathrm{Nu}$ is the Nusselt number, estimated in a porous material by Florio's formula ${ }^{8}$ :

$$
N u=a \operatorname{Re}^{b}
$$

where $a, b$ are numeric coefficients: $a=2.22 \cdot 10^{-6} b=0.703$. For a porous material the Reynolds number $\left[\operatorname{Re}=\frac{\rho u d}{\mu}\right]$ using the Darcy law (see eq. 3), is defined as ${ }^{8,9}$ :

$$
\operatorname{Re}=\frac{\rho_{\text {cool }}}{\mu_{\text {cool }}}\left[-\frac{B_{0}}{\mu_{\text {cool }}} \frac{d P}{d x}\right] d=-\frac{\rho_{\text {cool }} B_{0}^{1.5}}{\mu_{\text {cool }}^{2} \varepsilon} \frac{d P}{d x}
$$

where " $d$ " is a characteristic dimension of the porous material defined as:

$$
d=\frac{\sqrt{B_{0}}}{\varepsilon}
$$

other formulas suggested for " $d$ " are in the literature 9

The permeability coefficient $B_{0}$, of the porous material is modelled (crudely) as that of a packed bed of spheres of radius $r_{\mathrm{P}}$, so that $B_{0}$ can be evaluated by the Brennan-Kroliczek's (relationship between porosity and permeability) ${ }^{10}$ :

$$
B_{0}=\frac{\left(2 r_{p}^{2}\right) \varepsilon^{3}}{150(1-\varepsilon)^{2}}
$$

To evaluate in high speed flows the heat flux $q$ from the gas, and therefore $q^{*}$ needed by (1b), it is convenient to introduce the adiabatic wall temperature $T_{\text {ad.wall }}$ associated to the turbulent boundary layer heating due to viscosity:

$$
T_{a d . w a l l}=T_{\text {gas }}+r\left(T_{0 \text { gas }}-T_{\text {gas }}\right)
$$


where $r$ is the recovery factor, $r=\sqrt{\operatorname{Pr}}$ for laminar flow, $r=\sqrt[3]{\operatorname{Pr}}$ for turbulent flow, and $T_{\text {ogas }}$ the gas total temperature. For an ideal gas (at high temperature the real gas behaviour is similar to the ideal gas behaviour)

$$
T_{0 \text { gas }}=\left(1+\frac{\gamma-1}{2} M^{2}\right) T_{\text {gas }}
$$

and using the Bartz formula for $q$ (valid only in the region near the nozzle throat):

$$
q=q_{\text {Bartz }}=h_{\text {Bartz }}\left(T_{\text {ad.wall }}-T_{\text {surface }}\right)
$$

or:

$$
q_{\text {Bartz }}=h_{\text {Bartz }}\left[\left(1+\sqrt[3]{\operatorname{Pr}} \frac{\gamma-1}{2} M^{2}\right) T_{\text {gas }}-T_{\text {surface }}\right]
$$

with $T_{\text {surface }}$ the surface temperature of the porous material on the hot gas side.

The heat transfer coefficient using Bartz formula ${ }^{7,11}$ is

$$
h_{\text {Bartz }}=\left[\frac{0.026}{\left(D_{t}\right)^{0.2}}\left(\frac{\mu^{0.2} c_{P}}{\operatorname{Pr}^{0.6}}\right)_{0}\left(\frac{P_{0}}{c^{*}}\right)^{0.8}\left(\frac{D_{t}}{r_{\text {curv }}}\right)^{0.1}\right]\left(\frac{A^{*}}{A}\right)^{0.9} \sigma
$$

where $D_{t}$ is the throat nozzle diameter; $r_{\text {curv }}$ is the local radius of curvature; $A^{*}$ is the throat area and $\mathrm{A}$ is the area of a generic nozzle section. In (8) $c^{*}=P_{0} A^{*} / \dot{m}$ is the characteristic velocity and $\sigma$ is defined as:

$$
\sigma=\frac{1}{\left[\frac{1}{2} T_{\text {sufface }}\left(1+\frac{\gamma-1}{2} M^{2}\right)+\frac{1}{2}\right]^{0.8-0.2 \omega}\left[1+\frac{\gamma-1}{2} M^{2}\right]^{0.2 \omega}}
$$

with $\gamma=c_{P} / c_{V}$ the specific heat ratio of combustion gases; $\omega$ is the exponent of the viscositytemperature relation $\mu \propto T^{\omega}$ ( $\omega \cong 0.67$ for diatomic gases). The shielding effect due to transpiration (and $q^{*}$ ) can be evaluated using Stanton numbers. This effect scales with the "blowing” Stanton number ${ }^{12}$

$$
S t=\frac{\text { Heat tranfer in } \perp \text { flow direction }}{\text { Heat tranfer in } / / \text { flow direction }}=\frac{h}{\rho u C p}=\frac{N u}{\mathrm{Re} \cdot \operatorname{Pr}}
$$


The Stanton number $\mathrm{St}_{0}$ without blowing is

$$
S t_{0}=\frac{h_{\text {Bartz }}}{\rho_{\text {gas }} u_{\text {gas }} C p_{\text {gas }}}
$$

The shielding effect due to the boundary layer, from a simplified 1D thermal energy balance can be calculated from ${ }^{12}$

$$
\frac{S t}{S t_{0}}=\frac{\frac{B R}{S t_{0}} K_{M} K_{T}}{e^{\frac{B R}{S t_{0}} K_{M} K_{T}}-1}
$$

where:

$$
\begin{aligned}
& K_{M}=\left[\frac{(\text { Molecular weight })_{\text {gas }}}{(\text { Molecular weight })_{\text {coolant }}}\right]^{0.6} \\
& K_{T}=\left[\frac{T_{\text {ad.wall }}}{T_{\text {surface }}}\right]^{0.2 \ldots .0 .4}
\end{aligned}
$$

and where $B R$ is the Blowing Ratio defined below.

In conclusion, not the whole heat flux $\mathrm{q}_{\mathrm{Bartz}}$ reaches the wall, but only part of it, $q^{*}{ }_{\text {Bartz }}$ :

$$
\begin{aligned}
& h_{\text {Bartz }}^{*}=h_{\text {Bartz }} \frac{S t}{S t_{0}}=\frac{h_{\text {Bartz }}}{S t_{0}}\left[\frac{B R \cdot K_{M} \cdot K_{T}}{e^{\frac{B R}{S t_{0}} K_{M} K_{T}}-1}\right] \\
& q_{\text {Bartz }}^{*}=h_{\text {Bartz }}^{*}\left[T_{\text {ad.wall }}-T_{\text {surface }}\right]=q^{*} \text { of }(1 \mathrm{~b})
\end{aligned}
$$

\section{Blowing Ratio $(B R)$}

This critically important coefficient is the ratio between injected coolant mass flow rate and hot gas mass flow rate:

$$
B R=\frac{\rho_{\text {cool }} u_{\text {cool }}}{\rho_{\text {gas }} u_{\text {gas }}}=\frac{G_{\text {cool }}}{\rho_{\text {gas }} u_{\text {gas }}}
$$

The heat transfer between porous material and hot gas is controlled by the boundary layer thickness. A high $B R$ produces thicker boundary layers and a large heat transfer decrease 
between the wall and the hot gas, see (9f). However, it reduces also the effective nozzle throat area, an effect to be dealt with during the LRE design phase. A second critical aspect associated with BR is that the coolant injected trough the porous material in the nozzle is not used for propulsion, lowering $I_{s p}$. This negative effect is gauged by the Coolant Ratio $C R^{3}$ :

$$
C R=\frac{\left[\dot{m}_{\text {fuel }}\right]_{\text {transpiration }}}{\left[\dot{m}_{\text {fuel }}\right]_{\text {combustion }}}=\frac{\dot{m}_{\text {cool }}}{\dot{m}_{\text {fuel }}}
$$

$C R$ can be viewed as an efficiency parameter in transpiration cooling. A lower $C R$ indicates a better cooling system (higher efficiency), because less fuel is diverted and injected in the nozzle and so more can burn inside the combustion chamber.

\section{COMPUTATIONAL SOLUTION}

Equations (1-3) were solved iteratively until converged by a novel code using an explicit finite-difference method and by dividing the computational $0 \leq x \leq t$ domain into $\mathrm{N}$ nodes. The number of nodes $N$ was varied from 100 to 1000 to test grid independence. Using $N=1000$ produced acceptable convergence with a reasonable CPU time ( $2 \mathrm{~h}$ ); (see Appendix for details).

The transpiration cooling system has been assumed (and analysed) astride the nozzle throat, its overall length being $2 R_{\mathrm{t}}$ (figs 2-3).

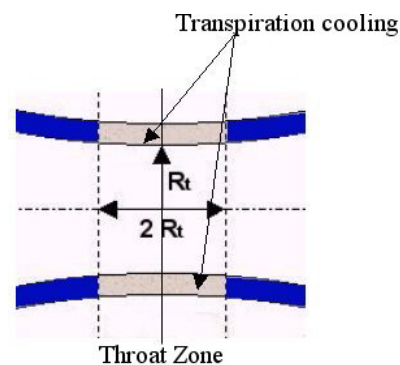

Fig. 2 Throat zone

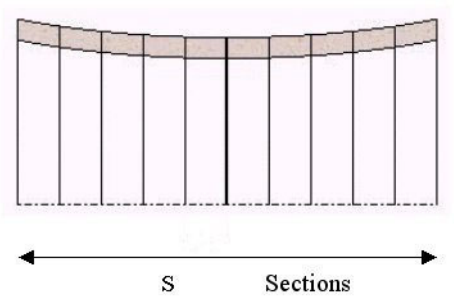

Fig. 3 Throat zone partition 
The $2 R_{\mathrm{t}}$ length of this region has been divided into " $S$ " individual sections or slices.

The heat transfer problem has been analysed as a $1 \mathrm{D}$ radial problem in every slice; the limit of this approach is that the heat exchange for a generic " $S$ " section is not influenced by heat exchange in the other sections; i.e., the heat flux in the axial direction is neglected. However, as results will show, this approximation may be reasonable and is also very convenient in a preliminary performance assessment or design. In fact, to start designing transpiration cooling optimisation section by section seems practical, resulting in a rough but quick coolant requirements assessment in a region (throat) where the thermodynamic properties of the hot gas (especially pressure) change rapidly.

In the present calculations every slice has been assumed $10 \mathrm{~mm}$ wide, this dimension having been found convenient (like $N=1000$ ) to speed up the numerical computation while maintaining accuracy (see Appendix).

Thermodynamic properties of the nozzle gas (pressure, temperature, density, viscosity, thermal conductivity, specific heats and their ratio) are considered radially uniform in all slices. Due to the high (supercritical) pressures typical of future LOX/HC LRE, density and specific heats were calculated with the Lee-Kesler equation of state for real gases ${ }^{4}$; viscosity and thermal conductivity were evaluated with Chung method ${ }^{4}$, using ANACYC software developed in collaboration with Avio ${ }^{13}$. ANACYC provides LRE nozzle preliminary sizing using (quasi-1D) adiabatic flow section by section and real gas (sub- and super-critical) properties. ANACYC is also integrated with CHEMKIN v $3.0^{\mathrm{TM}}$ to evaluate equilibrium gas composition. Therefore engine geometry, gas thermodynamic properties (composition, pressure, temperature, density, viscosity, thermal conductivity, specific heats and their ratio) are calculated at all $S$ sections.

Therefore the input to the transpiration cooling code developed in the present work is the ANACYC output, plus: 
1. Maximum wall temperature allowed, $T_{\max }$

2. Thermal conductivity of the wall material (without the effect of porosity), $k_{\text {wall }}$

3. Radius $r_{p}$ of spheres ideally composing the material according to its permeability model (typically, $r_{p}=0.01 \mathrm{~mm}$ )

4. Porosity law variation (porosity was changed in $0.5 \%$ steps)

The boundary conditions at every " $S$ " section were:

Coolant injection temperature, $T_{\text {cool }}$ in

Coolant injection pressure, $P_{\text {cool } i n}$

Temperature of wall in contact with coolant, $T_{\text {wall }}$

The transpiration cooling code produces as output:

1. Porous temperature $T_{\text {porous }}(x)$

2. Coolant temperature $T_{\text {cool }}(x)$

3. Coolant pressure $P_{\text {cool }}(x)$

4. Hot gas side wall temperature $T_{\text {surface }}$

5. Coolant "out" properties (temperature, pressure, speed, stay-time, density, viscosity, thermal conductivity, specific heats).

6. Wall thickness.

7. Heat flux (with and without shielding effect), using Bartz formula.

8. Total coolant mass used in transpiration.

9. Blowing ratio $B R$ (local and total).

10. Coolant ratio $C R$ (local and total). 
At every section the transpiration cooling code evaluates the wall thickness and consequently the coolant mass flow rate necessary to achieve wall temperature in the allowed range, see (12) below.

The solution found must meet preliminary optimisation criteria such as:

1. Low coolant ratio $C R$.

2. Low coolant maximum temperature: the methane coolant is subjected to coking (cracking). Carbon deposits might obstruct pores, altering the heat exchange. Recent studies ${ }^{14}$ demonstrate no coking problem for pure methane, so long as its temperature stays below $750 \mathrm{~K}$.

3. Low max wall temperature: this is the critical requirement for any cooling system (lower temperatures enhance engine life and paves the way toward reusability); however, a too low wall temperature is a poor solution in terms of $I_{s p}$, because it implies high coolant flow-rates. Temperatures were imposed in the range: $\left[T_{\max }-1 \%\right] \leq T_{\text {wall_allowed }} \leq T_{\max }$

This constraint obtain very low thermal gradients in the axial direction, so that neglecting axial heat transfer in the model may be considered a reasonable approximation. 


\section{METHANE PHASE CHANGE}

The mathematical model of eqs. $1-3$ predicts porous material temperature $T_{\text {porous }}(x)$, coolant temperature $T_{\text {cool }}(x)$, and coolant pressure $P_{\text {cool }}(x)$ at every nozzle slice; an example of the numerical solution is provided by figs. $4-7$, that show temperature profile of the porous material and temperature, pressure and density profile of the coolant. They are obtained with the following data input: slice number $\mathrm{n}^{\circ} 27$ (last nozzle section); coolant injection temperature $T_{\text {cool_in }}=140 \mathrm{~K}$; coolant injection pressure $P_{\text {cool in }}=200$ bar; thermal conductivity $k_{\text {wall }}=20 \mathrm{~W} / \mathrm{mK}$; maximum wall temperature allowed $T_{\max }=500 \mathrm{~K}$; slice porosity $\varepsilon=13 \%$.

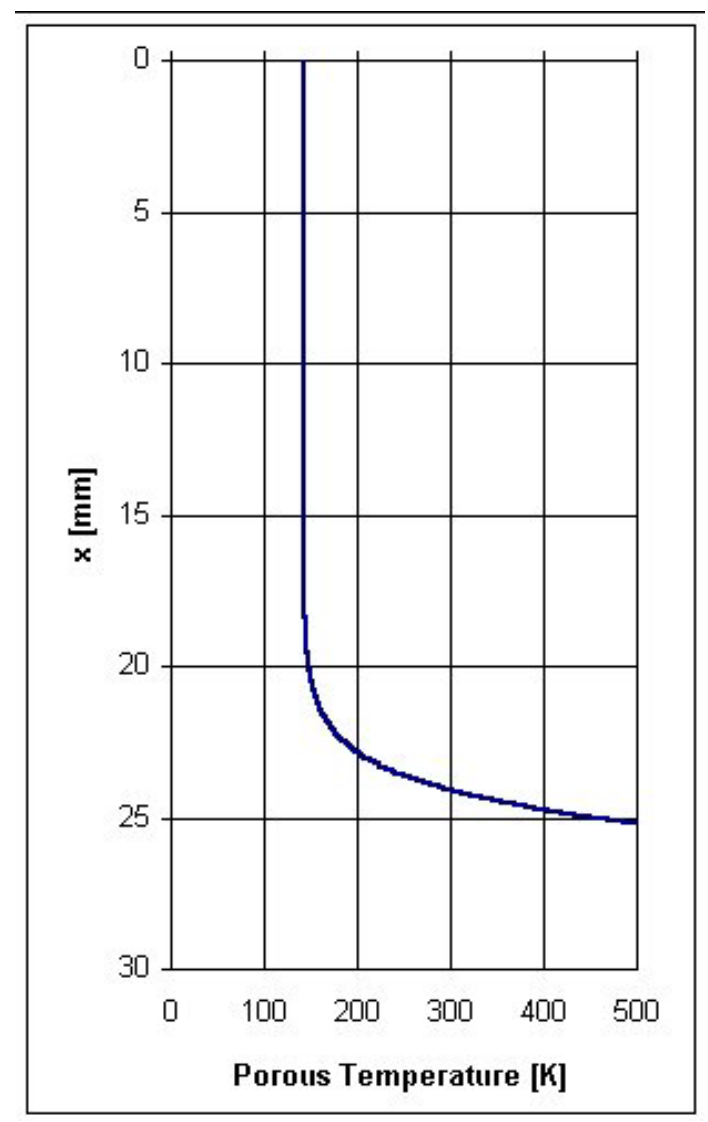

Fig. 4 Porous temperature profile

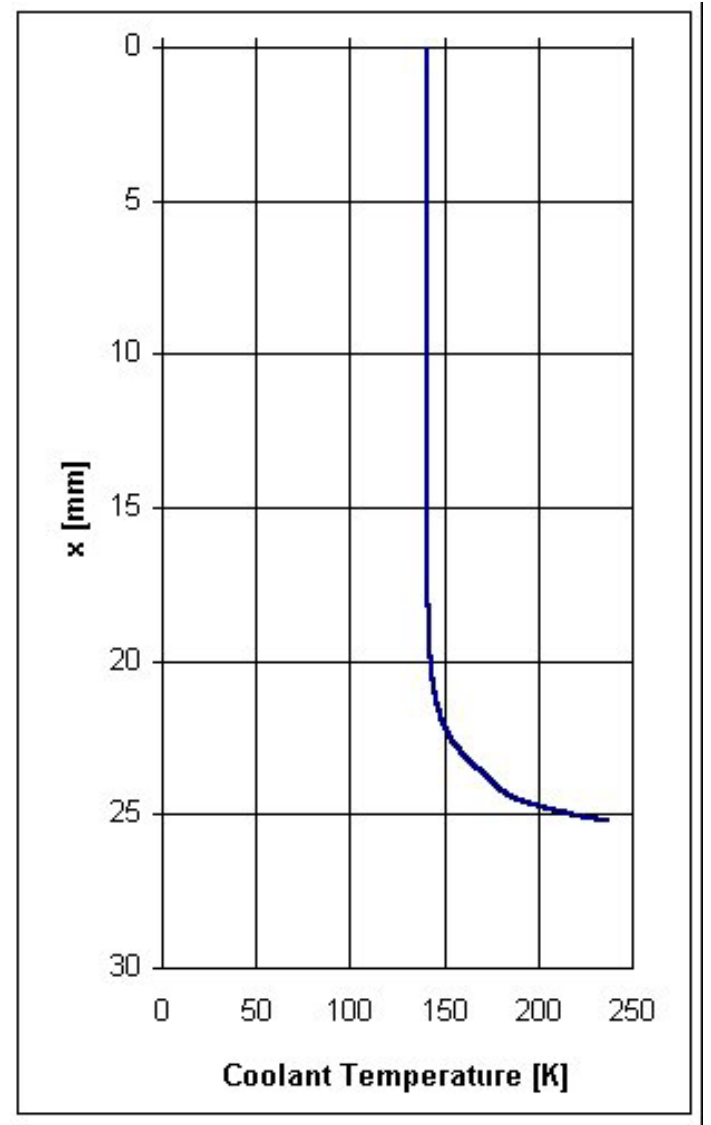

Fig. 5 Coolant temperature profile 


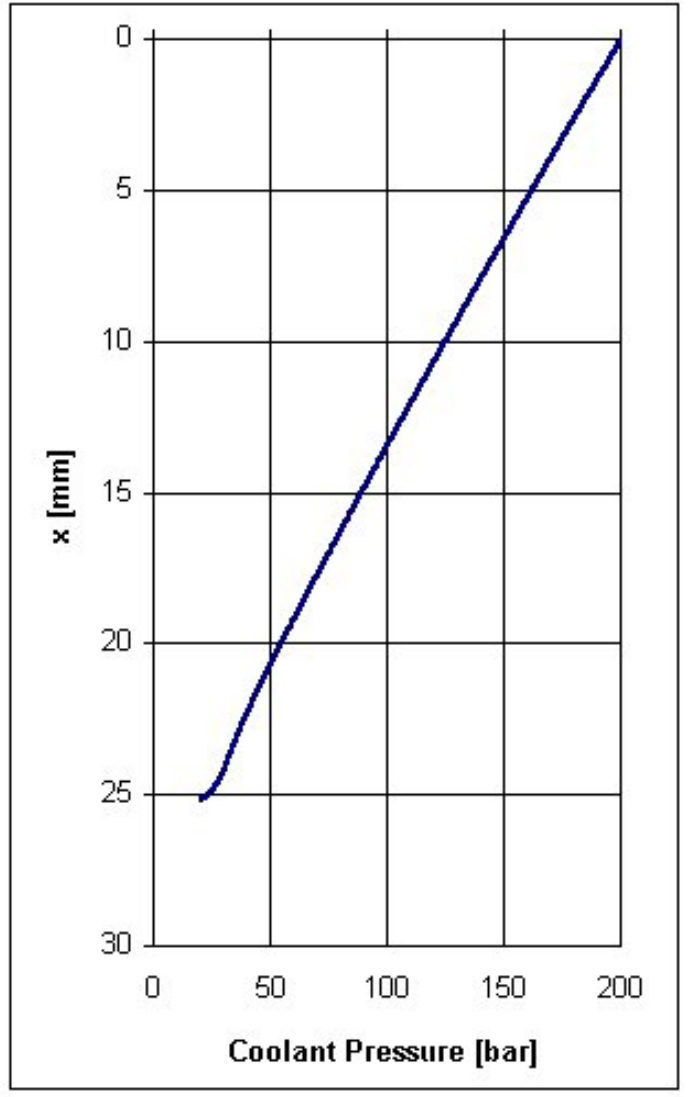

Fig. 6 Coolant pressure profile

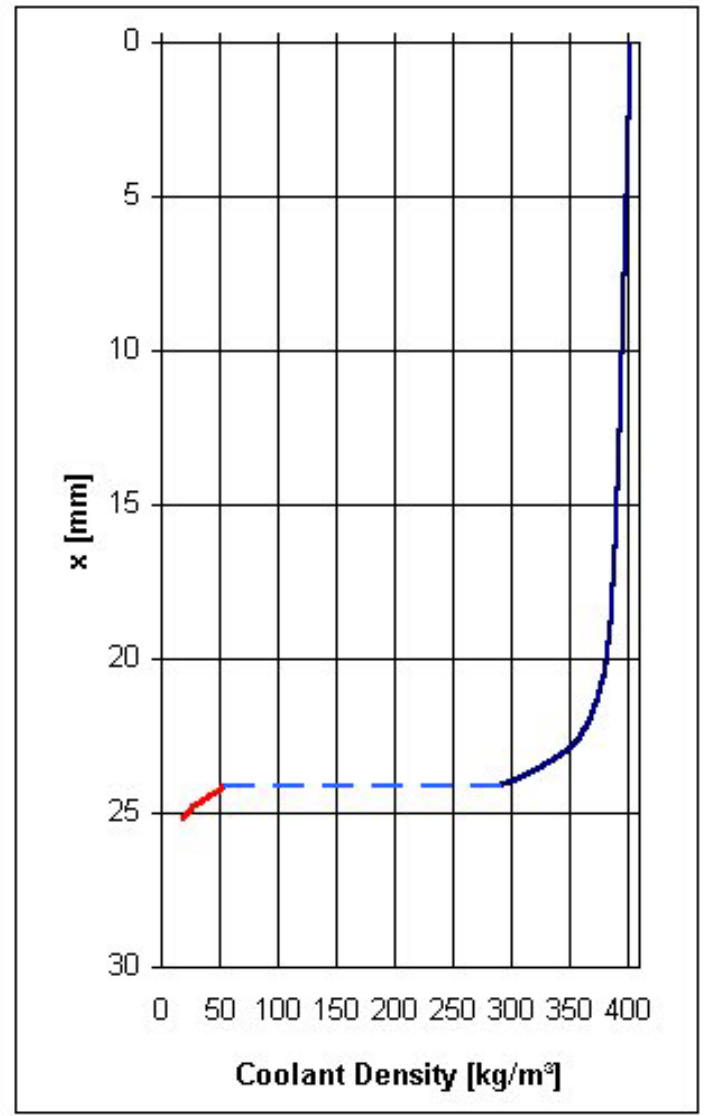

Fig. 7 Coolant density profile

Note that at temperature $T_{\text {cool-in }}=140 \mathrm{~K}$ and with $P_{\text {cool-in }}=200$ bar, methane is liquid and its density is about $402.88 \mathrm{~kg} / \mathrm{m}^{3}$. During its path into the porous material methane becomes warmer and its pressure decreases; if the wall thermal conductivity is about $k_{\text {wall }}=20 \mathrm{~W} / \mathrm{mK}$ a phase change (liquid to vapour) occurs; consequently results presented in the parametric analysis below overestimate the coolant mass requirement, since the mathematical model (assuming supercritical conditions) does not include the latent heat of vaporization of methane. This effect it is important in the last few nozzle sections ( 8 of 27 total number sections examined), where methane must become sub-critical (coolant pressure less than methane critical pressure $P_{c r}=46.0$ bar and coolant temperature less than methane critical temperature $T_{c r}=190.4 \mathrm{~K}$ ). No phase change (liquid to vapour) occurs at $k_{\text {wall }}=100 \mathrm{~W} / \mathrm{mK}$. Phase change of $\mathrm{CH}_{4}$ becomes a significant problem only for very poor material conductivity. 
Avoiding methane phase change is a design issue because the expansion causes a sharp expansion e.g., see fig. 7 , methane density changes from $\approx 290 \mathrm{~kg} / \mathrm{m}^{3}$, to vapour density $\approx 54$ $\mathrm{kg} / \mathrm{m}^{3}$. This can cause structural failure of the porous material.

\section{PARAMETRIC ANALYSIS RESULTS}

The first three parameters varied were:

Wall material thermal conductivity $k_{\text {wall }}=20$ and $100 \mathrm{~W} / \mathrm{mK}$ (relatively low).

Coolant injection temperature $\mathrm{T}_{\text {cool-in }}=140 \mathrm{~K}$ (below the methane critical temperature $\mathrm{T}_{\mathrm{cr}}=$ $190,4 \mathrm{~K}$ ) and $300 \mathrm{~K}$ (above critical temperature).

Maximum wall temperature allowed $T_{\max }=500,600$ and $700 \mathrm{~K}$.

Fixed inputs in this particular analysis were:

Combustion chamber pressure: $P_{c o m b}=200$ bar, also equal to coolant injection pressure $P_{\text {cool-in }}$ Porosity $\varepsilon=16 \%$ for the first nozzle slice/section; then decreased by $0.5 \%$ every 4 sections along nozzle.

Methane injection temperature: $T_{\text {fuel-in }}=300 \mathrm{~K}$.

Oxidant (LOX) injection temperature: $T_{o x-i n}=100 \mathrm{~K}$.

Equivalence ratio: $\Phi=\frac{\left(\begin{array}{c}\dot{m_{o x}} \\ \hline \dot{m_{f u e l}}\end{array}\right)_{s t}}{\left(\begin{array}{c}\dot{m_{o x}} \\ \dot{m_{f u e l}}\end{array}\right)} \frac{3.989}{\left(\begin{array}{c}\dot{m_{L O X}} \\ \cdot \\ m_{C H_{4}}\end{array}\right)}=1.3$

Thrust: $2 \cdot 10^{6} \mathrm{~N}$ 
Effect of the three parameters on:

Wall thickness (fig. 8, 9)

Increasing $T_{\max }$ or $k_{\text {wall }}$ increases wall thickness $t$ due to the lower mass flow rate of coolant required; the lower pressure drop and the pressure matching condition together result in raising wall thickness.

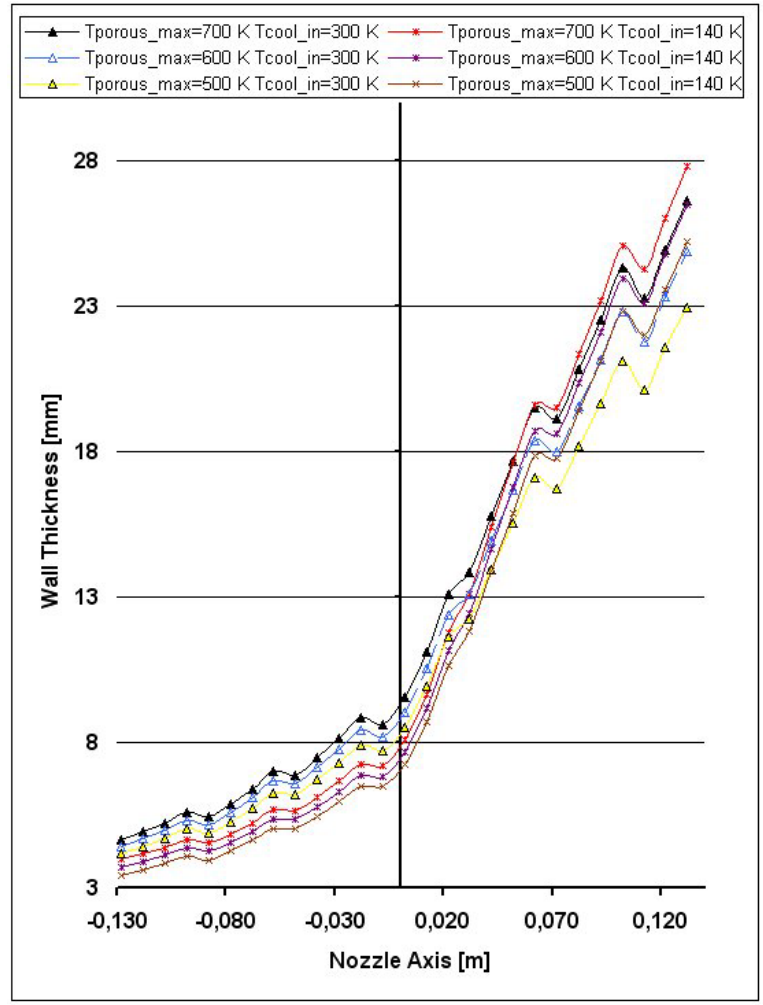

Fig. 8 Wall thickness $\left[k_{\text {wall }}=20 \mathrm{~W} / \mathrm{mK}\right]$

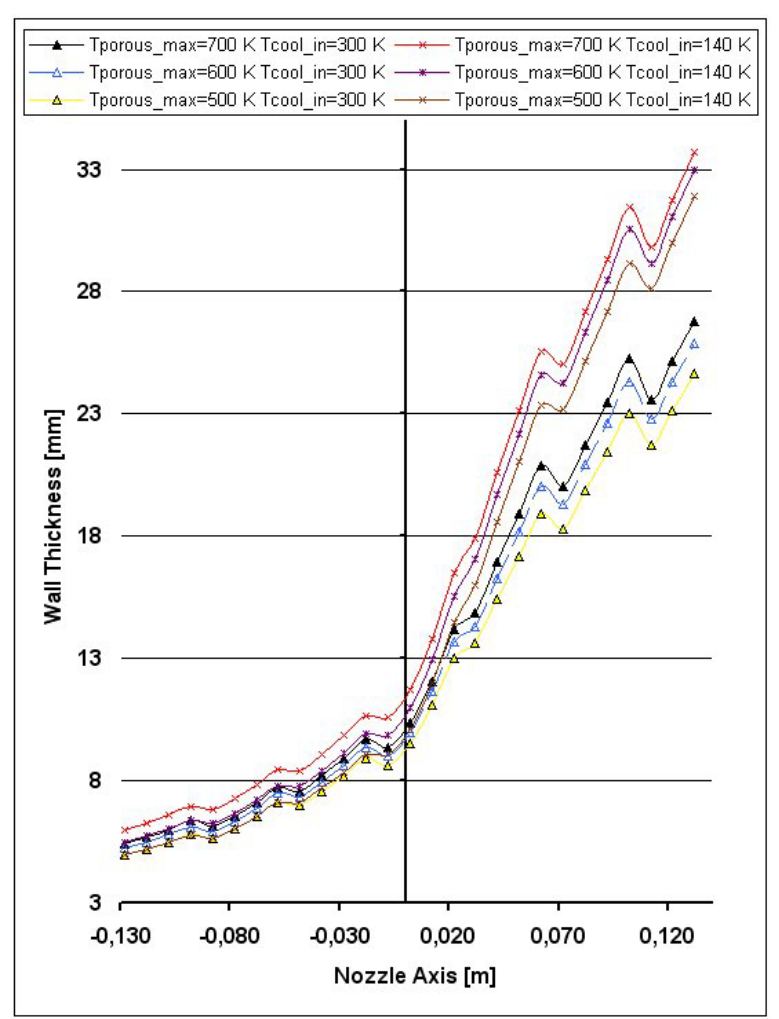

Fig. 9 Wall thickness $\left[k_{\text {wall }}=100 \mathrm{~W} / \mathrm{mK}\right]$

Coolant speed (fig. 10, 11)

Coolant speed $u_{\text {cool-out }}$ increases if $T_{\max }$ increases and the same occurs when raising the coolant injection temperature $T_{\text {cool-in }}$. $k_{\text {wall }}$ becomes important only at lower temperatures.

Note that coolant velocity is low, e.g. at most $1.6 \mathrm{~m} / \mathrm{s}$; so it is its flowrate (and not its injection speed) that thickens the thermal boundary. 


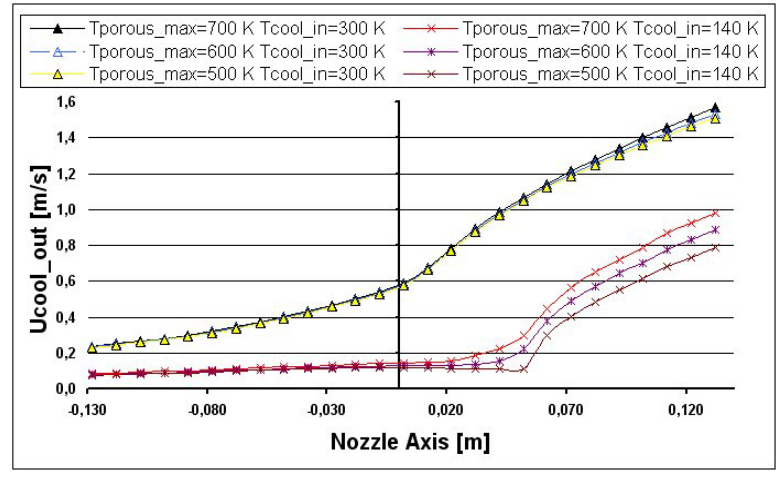

Fig. 10 Coolant velocity $\left[k_{\text {wall }}=20 \mathrm{~W} / \mathrm{mK}\right]$

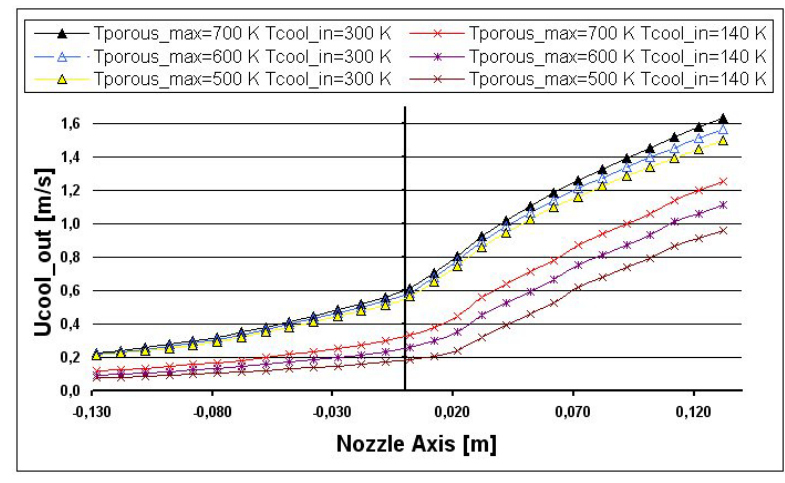

Fig. 11 Coolant velocity $\left[k_{\text {wall }}=100 \mathrm{~W} / \mathrm{mK}\right]$

Coolant temperature (fig. 12, 13)

Coolant temperature $T_{\text {cool-out }}$ is increased by raising $T_{\max }$ and $T_{\text {cool-in }}$. Raising $k_{\text {wall }}$ also raises significantly $T_{\text {cool-out }}$
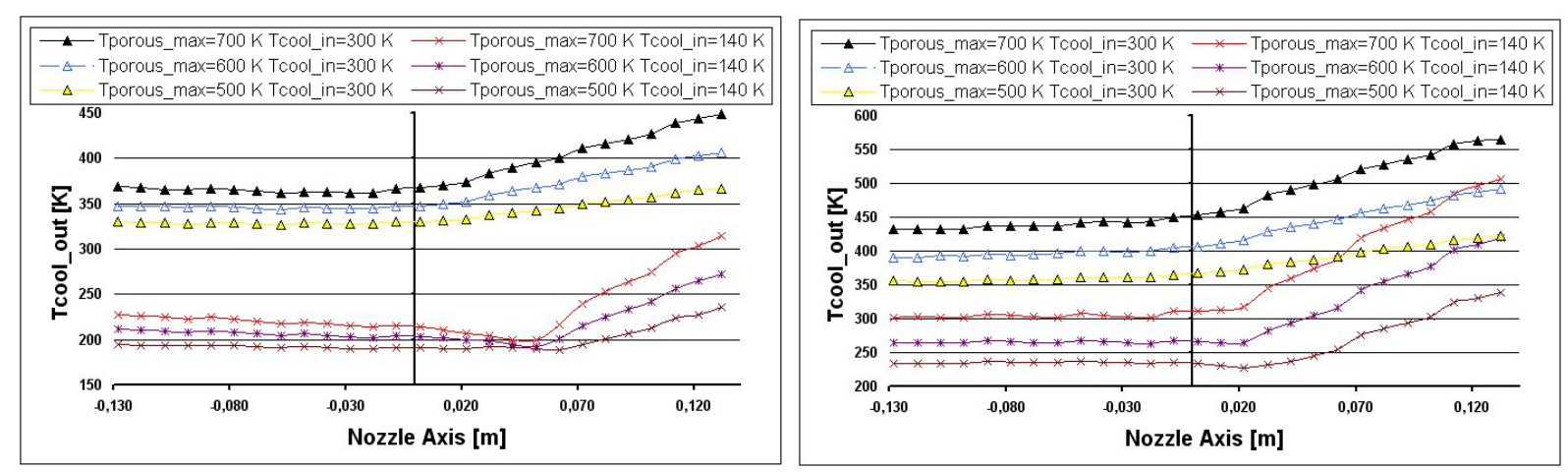

Fig. 12 Coolant temperature $\left[k_{\text {wall }}=20 \mathrm{~W} / \mathrm{mK}\right]$ Fig. 13 Coolant temperature $\left[k_{\text {wall }}=100 \mathrm{~W} / \mathrm{mK}\right]$

Blowing Ratio (fig. 14, 15)

A higher $B R$ shields heat more effectively; conversely, if lower $T_{\max }$ are desired $B R$ must be increased. Notice that raising $T_{\text {cool-in }}$ from $140 \mathrm{~K}$ to $300 \mathrm{~K}$ raises $B R$ by $10 \%$ : since coolant temperature depends on engine cooling and operation this means that effective cooling of the 
throat region is possible relatively independent of overall engine configuration. Raising thermal conductivity tends to reduce $B R$ by as much as $20 \%$.

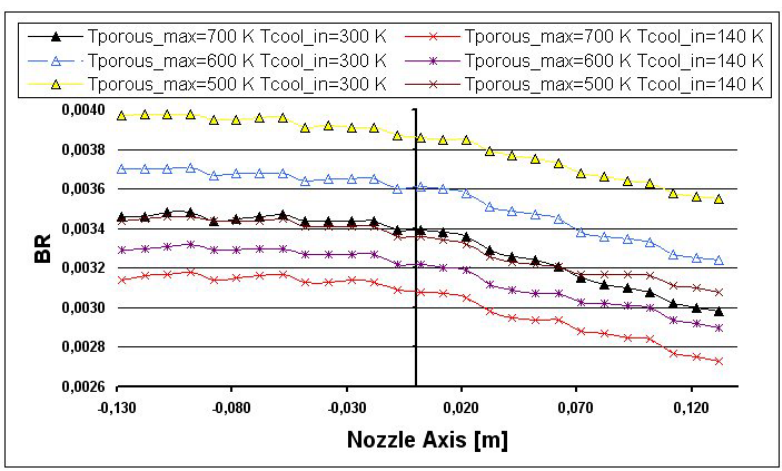

Fig. 14 Blowing Ratio $\left[k_{\text {wall }}=20 \mathrm{~W} / \mathrm{mK}\right.$ ]

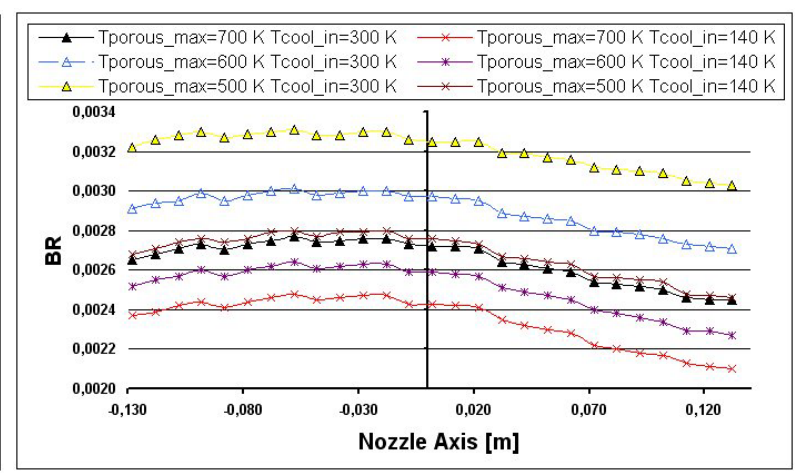

Fig. 15 Blowing Ratio $\left[\mathrm{k}_{\mathrm{wall}}=100 \mathrm{~W} / \mathrm{mK}\right]$

\section{Coolant Ratio (fig. 16, 17)}

Just as $B R, C R$ increases by $10 \%$ if $T_{\text {cool-in }}$ is raised or $T_{\max }$ is lowered High heat flux results in a higher coolant ratio near the nozzle throat. Likewise, larger $k_{\text {wall }}$ reduces significantly $C R$ (about 20\%); the total $C R$ (integrated over all S slices), is in Table 1.

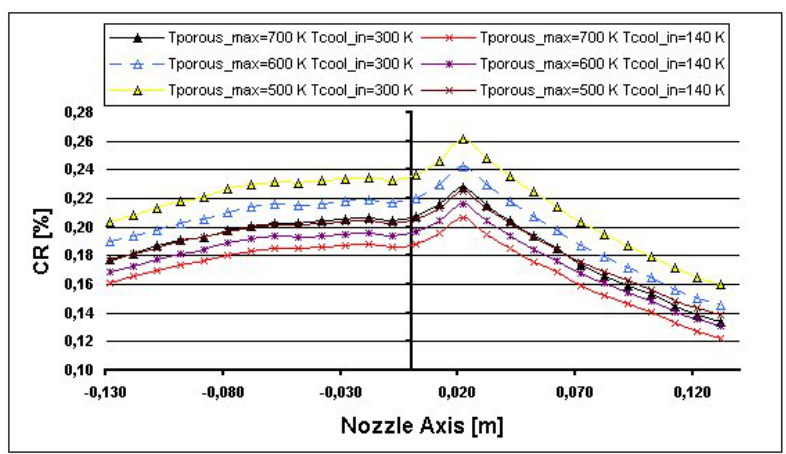

Fig. 16 Coolant Ratio $\left[k_{\text {wall }}=20 \mathrm{~W} / \mathrm{mK}\right]$

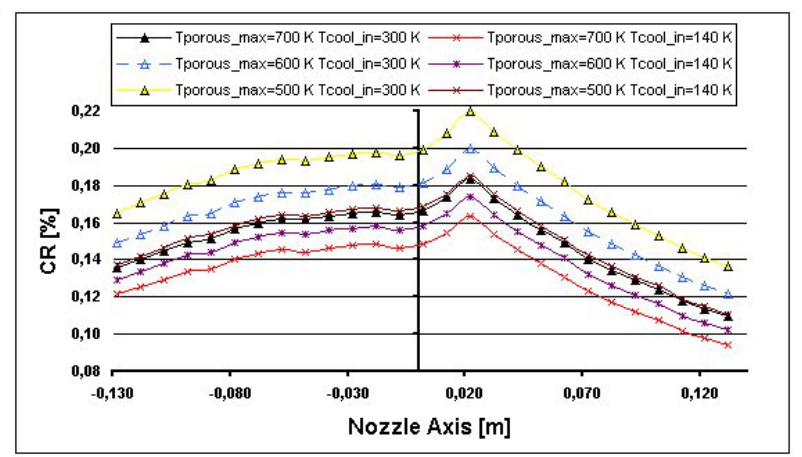

Fig. 17 Coolant Ratio $\left[k_{\text {wall }}=100 \mathrm{~W} / \mathrm{mK}\right]$ 


\begin{tabular}{cccc}
\hline \hline $\mathrm{k}_{\text {wall }}[\mathrm{W} / \mathrm{mK}]$ & $\mathrm{T}_{\max }[\mathrm{K}]$ & $\mathrm{T}_{\text {cool-in }}[\mathrm{K}]$ & $\mathrm{CR}_{\text {tot }}[\%]$ \\
\hline 20 & 500 & 300 & 5.845 \\
20 & 600 & 300 & 5.417 \\
20 & 700 & 300 & 5.073 \\
100 & 500 & 140 & 5.070 \\
20 & 500 & 300 & 4.909 \\
20 & 600 & 140 & 4.844 \\
100 & 700 & 140 & 4.626 \\
100 & 600 & 300 & 4.440 \\
100 & 500 & 140 & 4.104 \\
100 & 700 & 300 & 4.056 \\
100 & 600 & 140 & 3.843 \\
\hline \hline
\end{tabular}

Table 1: Total CR for the entire throat zone

Coolant mass flow rate $G_{\text {cool }}($ fig. 18, 19)

$G_{\text {cool }}$ peaks at the throat section and is influenced by the way porosity changes along the nozzle axis. Predictably, $G_{\text {cool }}$ is larger using a warmer coolant or when lowering $T_{\max }$.
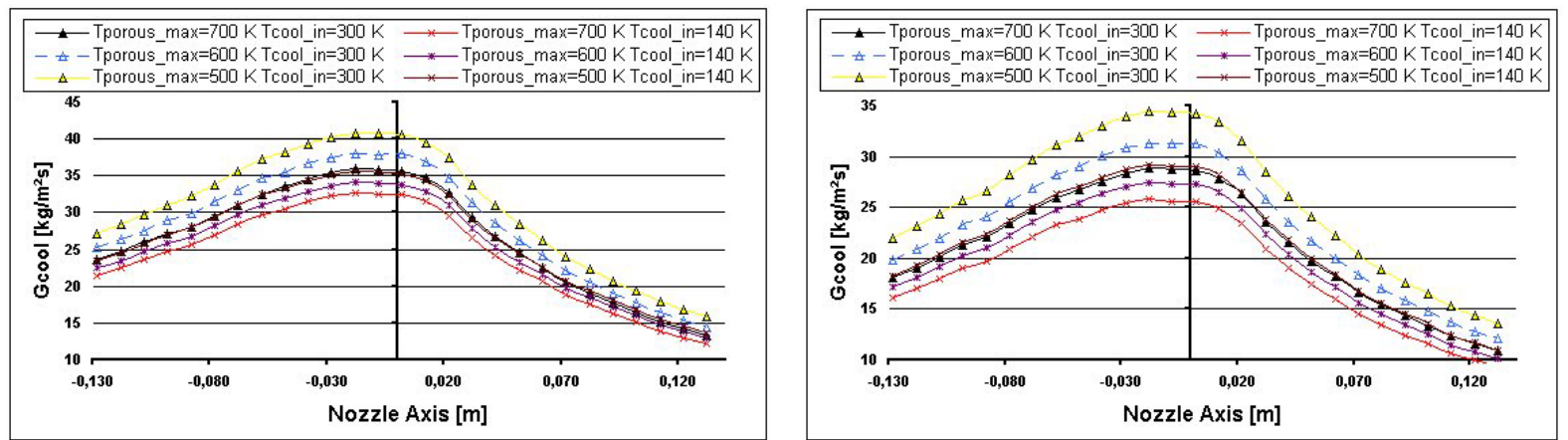

Fig. 18 Coolant Mass Flow Rate $\left[k_{\text {wall }}=20\right.$ W/mK] Fig. 19 Coolant Mass Flow Rate $\left[k_{\text {wall }}=100 \mathrm{~W} / \mathrm{mK}\right]$ 
Effect of porosity law

Technologically, porosity is probably the most important parameter explored in this study.

A parametric analysis of the effect of porosity has been performed assuming the following:

Coolant injection temperature $T_{\text {cool_in }}=300 \mathrm{~K}$

Thermal conductivity $k_{\text {wall }}=20 \mathrm{~W} / \mathrm{mK}$

Maximum wall temperature allowed $T_{\max }=600 \mathrm{~K}$

The remaining input data were left unchanged. The porosity $\varepsilon$ has been changed using two different strategies:

1. Different porosities for the first nozzle section:

$\varepsilon=15 \%, 16 \%$ and $17 \%$

Although this is a narrow range, it is consistent with reasonable values for wall thickness.

Porosity higher than $17 \%$ causes a wall thickness at the last nozzle slice $>31 \mathrm{~mm}$, while porosity under $15 \%$ causes an extremely thin first nozzle section $<3.6 \mathrm{~mm}$.

2. Porosity stepped down along the nozzle axis, in three ways:

Decreasing by $0.5 \%$ every 4 sections $(4 \mathrm{~cm})$, or

Decreasing by $0.5 \%$ every 3 sections $(3 \mathrm{~cm})$, or

Decreasing by $0.5 \%$ every 2 sections $(2 \mathrm{~cm})$.

Porosity values in this parametric analysis are consistent with those used in a recent test at the DLR, (Lampoldshausen German Aerospace Centre). ${ }^{15}$ In this facility a carbon-carbon material has been tested with $\varepsilon \approx 20 \%$. A pyrolysis process can obtain porosity of about $15 \%$ and lower, by a process allowing porosity to be varied with high reliability and precision. 
Unfortunately test data of [15] could not be compared to predictions presented here, due to large differences in geometry, combustion chamber pressure and especially coolant utilized (hydrogen).

Fig 20, 21 show how porosity (obtained with both strategies 1 and 2) can reduce $t$. In fact, $t$ varies from $7 \mathrm{~mm}$ up to $31 \mathrm{~mm}$, a substantial range, due to the porosity changing along the nozzle axis. In fact, lowering porosity lowers also material permeability and raises pressure drop so that, to meet the pressure constraint, the wall thickness must also be reduced.

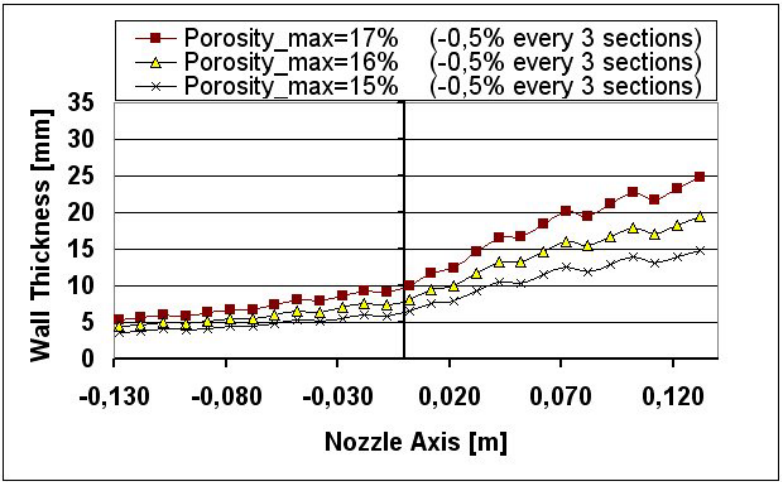

Fig. 20 Wall thickness [different porosity at the first section]

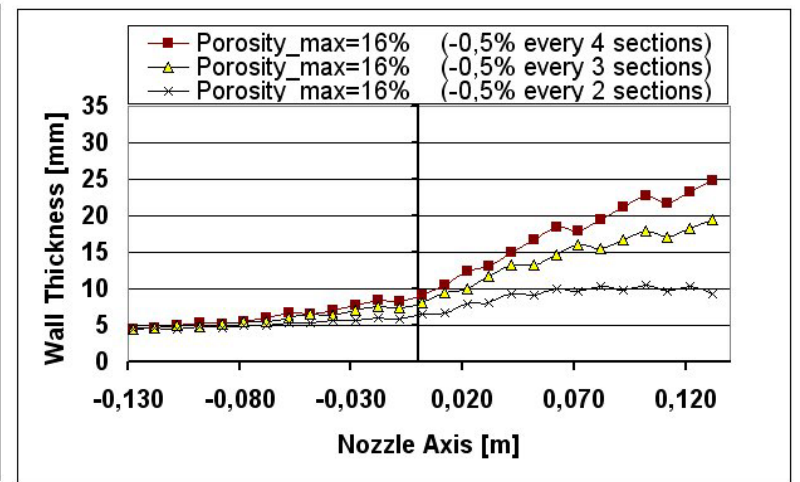

Fig. 21 Wall thickness [porosity stepped down in decrements]

Coolant velocity is weakly influenced by porosity, (by no more than $1.5 \%$ ) and remains very low, $\approx 1.6 \mathrm{~m} / \mathrm{s}$ (the highest value occurs at the last section, where the maximum in the coolant pressure gradient occurs).

In the low range porosity increases heat transfer between the coolant and the porous material (higher volumetric heat transfer coefficient, and $k_{\text {porous }}$ nearer to $k_{\text {wall }}$ ) so that $T_{\text {cool-out }}$ is higher (fig. 22, 23). 


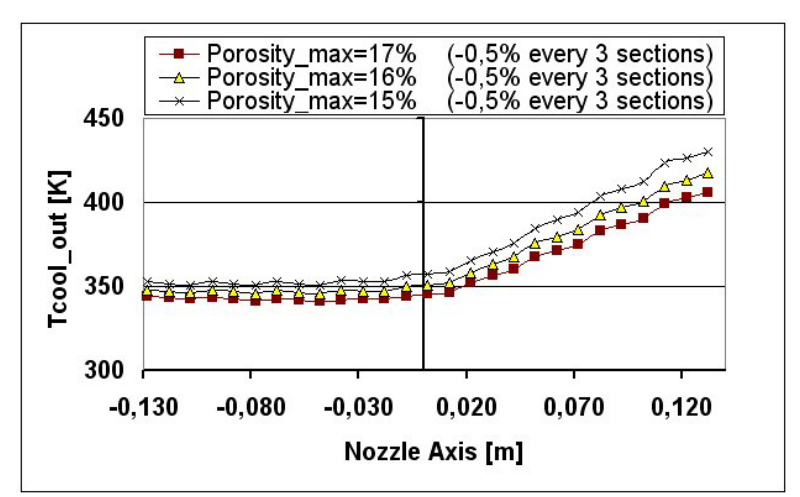

Fig. 22 Coolant temperature [different porosity

at the first section]

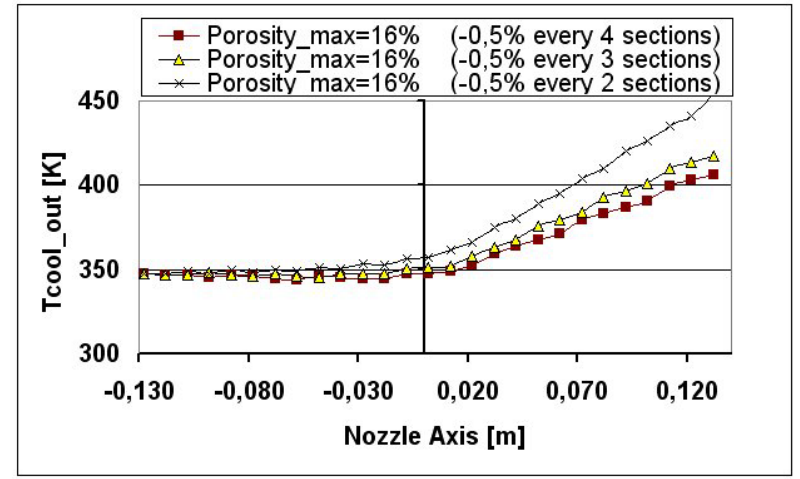

Fig. 23 Coolant temperature [porosity stepped down in decrements]

Lower porosity lowers also significantly $B R$ (figs. 24-25), the $C R$ (see figs. 26-27 and Table

2 ) and the coolant mass flow rate $G_{c o o l}$.

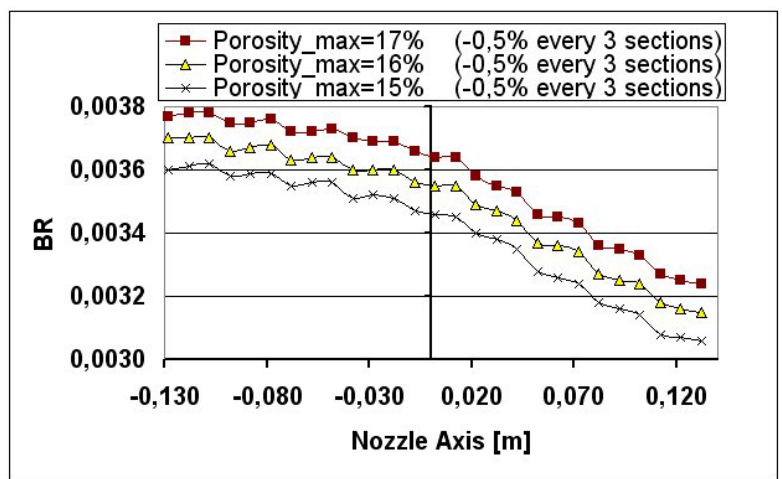

Fig. 24 Blowing Ratio [different porosity at the first section]

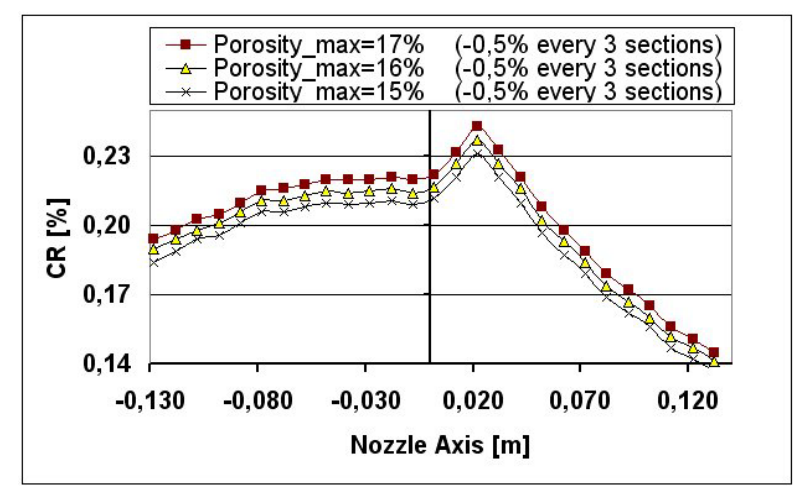

Fig. 26 Coolant Ratio [different porosity at the first section]

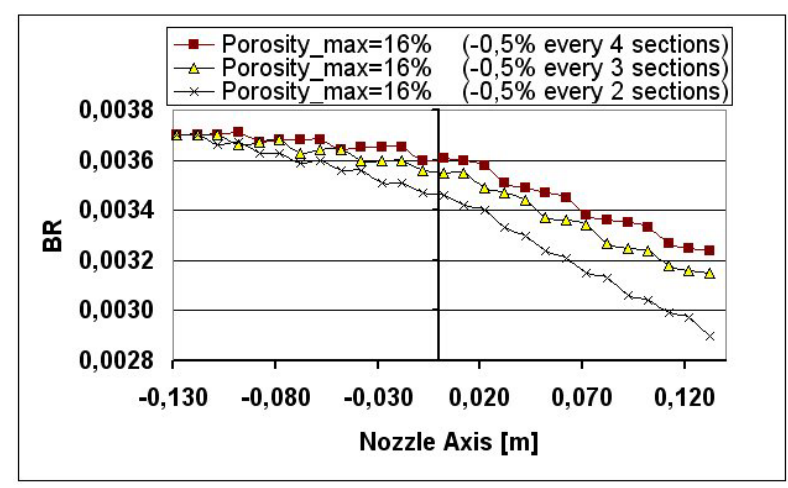

Fig. 25 Blowing Ratio [porosity stepped down in

decrements]

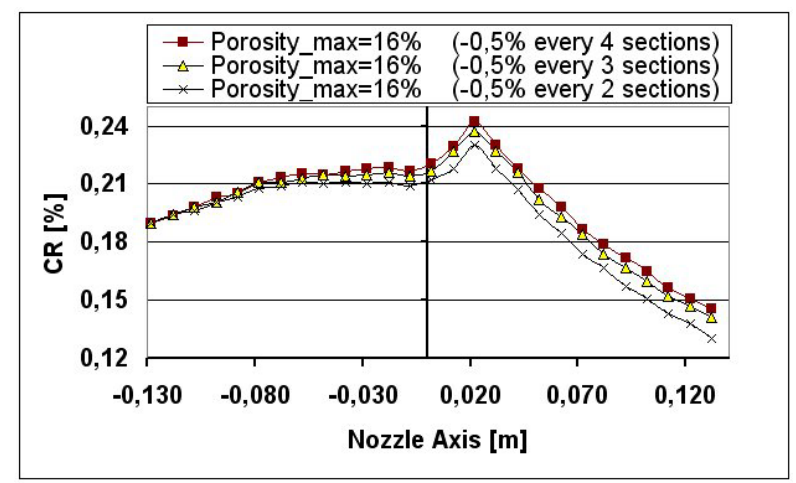

Fig. 27 Coolant Ratio [porosity stepped down in decrements] 


\begin{tabular}{clc}
\hline \hline Porosity & Porosity law variation & $C R_{\text {tot }}[\%]$ \\
$($ First section $)$ & & \\
\hline$\varepsilon=17 \%$ & Decrease $0,5 \%$ every 4 sections & 5.547 \\
$\varepsilon=17 \%$ & Decrease $0,5 \%$ every 3 sections & 5.474 \\
$\varepsilon=16 \%$ & Decrease $0,5 \%$ every 4 sections & 5.417 \\
$\varepsilon=16 \%$ & Decrease $0,5 \%$ every 3 sections & 5.342 \\
$\varepsilon=17 \%$ & Decrease $0,5 \%$ every 2 sections & 5.323 \\
$\varepsilon=15 \%$ & Decrease $0,5 \%$ every 4 sections & 5.282 \\
$\varepsilon=15 \%$ & Decrease $0,5 \%$ every 3 sections & 5.204 \\
$\varepsilon=16 \%$ & Decrease $0,5 \%$ every 2 sections & 5.187 \\
$\varepsilon=15 \%$ & Decrease $0,5 \%$ every 2 sections & 5.034 \\
\hline \hline
\end{tabular}

\section{Table 2 : $\quad$ Total CR (entire throat zone)}

In conclusion, lowering porosity to the "right" (minimum) range has a positive effect on transpiration cooling. This is the result of competition between its effect on lowering thickness (thus less material to cool) and its effect on lowering $B R$ (lower shielding effect on heat transfer).

\section{CONCLUSIONS}

The results of this study suggest transpiration cooling has the potential for lowering nozzle throat wall temperature and thus enhancing engine life, with the potential pay-off of reduced operation and maintenance cost. 
Additionally, the regenerative cooling system feeding $\mathrm{LCH}_{4}$ to the transpiration section will not require high speed flow in the throat channels, implying the lower pressure drop in the coolant circuit may reduce turbo-pump power.

Very low wall temperatures $(500-700 \mathrm{~K})$ appear within reach with a moderate coolant use (less than 5\%; minimum: $3.6 \%$ ), and even for materials with thermal conductivities well below those used in conventional cooling (e.g., 4 times lower than Narloy $\mathrm{Z}^{\mathrm{TM}}$ ).

The main factors affecting transpiration cooling are predicted to be:

Material thermal conductivity: higher $k_{\text {wall }}$ lowers mass flow rate, but the engine may result heavier, since wall thickness increases.

Porosity: an appropriate porosity drives more intense heat transfer between coolant and porous material and so lowers coolant flow-rate. Porosity control is therefore a critical and enabling technology.

Coolant injection temperature: lower temperature achieves better heat shielding, but very low inlet temperature (e.g., $T_{\text {cool-in }}=140 \mathrm{~K}$ ) may favour vaporization of methane inside the porous material.

Transpiration cooling is not meant to replace the entire regenerative cooling system, but is rather seen as a local solution, very effective in the nozzle throat region. Using transpiration cooling to cool an entire engine would pose unacceptable coolant flow-rate demands. The two cooling strategies must therefore be integrated, and with this caveat in mind design complexity can also be avoided.

Finally some design hints are available by the parametric analysis conducted.

The partition of the nozzle throat into physically different slices is probably also a smart solution to avoid transverse (oblique) coolant flow in the axial direction and toward lower exit pressure (due to the presence of a pressure gradient along the same direction). This may be practically achieved by using a coating inhibiting porosity between two adjacent slices. 
Moreover, as shown by results in this work, this solution lends itself to optimisation (minimization of coolant requirement) and to a better control of parameters that influenced the transpiration cooling system. The main ones are:

Porosity: uniform porosity slice by slice is required to avoid danger heat transfer peaks.

Wall thickness: the system is sensitive to even small thickness changes.

\section{APPENDIX: \\ COMPUTATIONAL TIME AND NUMERICAL ACCURACY}

Numerical solutions used a uniform grid with $N=1000$ nodes. A higher number of nodes was found unnecessary and not advisable due to a rapid growth of computational time.

Computational time is ruled by:

1. Total grid nodes number:

Higher accuracy and computational time have opposite trends with grid nodes number $N$. For example, using a Pentium IV $1.8 \mathrm{GHz}$ PC computational times are: 10-20 minutes for a grid with $N=100$ nodes; $100-200$ minutes for a grid with $N=1000$ nodes; with the same $N$, CPU time differences occur for different values for the coolant injection temperature (a boundary condition).

2. Number of slices "S":

"S" was fixed at $27(270 \mathrm{~mm}$.).

3. Computational time varies for each of the "S" slices. This is mostly due to the LeeKesler equation of state. This equation is highly accurate for real gases, but is also CPU intensive; for example, calculating density needs many iterations ${ }^{4}$ (order of 
$10 \div 10^{3}$ ) depending on pressure and temperature, and resulting in different CPU times at different grid nodes.

4. Convergence criteria:

Higher precision (lower error tolerance) affected computational time: for the porous temperature profile we accepted an error for the heat flux $|D q|<10 \mathrm{~W} / \mathrm{m}^{2}$, compared to typical heat fluxes $\approx 10^{7} \mathrm{~W} / \mathrm{m}^{2}$. For pressure matching (coolant exit pressure must equal hot gas pressure) we accepted an error $|D p|<10 P a$, compared to pressure $\approx 10^{6} \div 10^{7} \mathrm{~Pa}$. The constraint on maximum wall temperature is eqn. (12).

5. Convergence algorithm:

This algorithm is an evolution of the classical bisection method called "secants method with unsteady extreme points". Figure 28 illustrates method applied to a generic function $f(x)$ to find its zero at $\xi$ in the range $[a, b]$. Iterations are calculated by the formula

$$
x_{n+1}=x_{n}-f\left(x_{n}\right) \frac{x_{n}-x_{n-1}}{f\left(x_{n}\right)-f\left(x_{n-1}\right)}
$$

where $x_{0}, x_{1}$ are known.

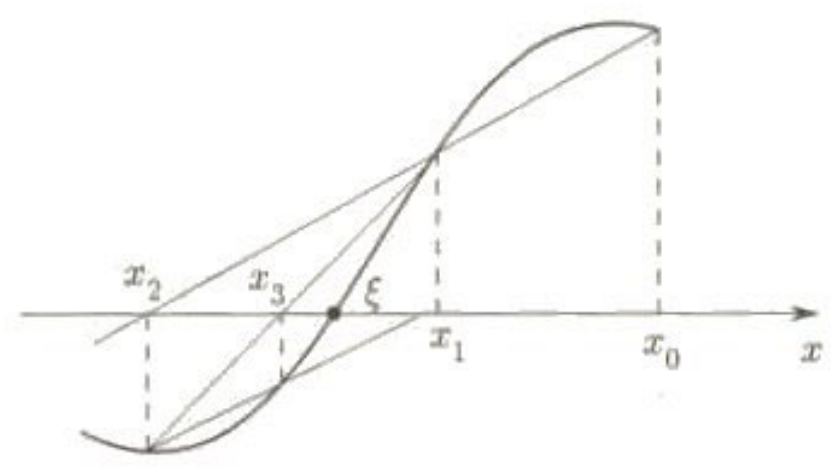

Fig. 28 Secants method with unsteady extreme points 
6. Grid independency:

This was assessed in the following case:

Coolant injection pressure: $P_{\text {cool-in }}=200$ bar; coolant injection temperature: $T_{\text {cool-in }}=$ $300 \mathrm{~K}$; wall temperature (coolant side): $T_{\text {wall }}=300 \mathrm{~K}$; maximum wall temperature allowed: $T_{\max }=600 \mathrm{~K}$; wall material thermal conductivity: $k_{\text {wall }}=20 \mathrm{~W} / \mathrm{mK}$; porosity for the first nozzle section: $\varepsilon=16 \%$; then porosity is decreased by $0.5 \%$ every 4 sections along nozzle axis. Equivalence ratio: $\Phi=1.3$

Nodes for the uniform grid: $N=1000$ and 100 uniformly spaced nodes. The percent error of a generic quantity " $G$ ” was defined:

$$
\text { Error }_{G}=\frac{G_{[N=1000]}-G_{[N=100]}}{G_{[N=1000]}}
$$

This error is lower for the upstream nozzle slices (see figs. 30, 32), growing along the nozzle, since a radially thicker slice results in larger node spacing, lowering numerical precision. Table 3 summarizes the maximum error.

\begin{tabular}{lccc}
\hline \hline Output & $N=1000$ & $N=100$ & Error [\%] \\
\hline Thickness $t[\mathrm{~mm}]$ & 18.3878 & 18.2399 & +0.80 \\
$T_{\text {cool-out }}[\mathrm{K}]$ & 406.12 & 397.73 & +2.07 \\
$B R$ & 0.00324 & 0.00331 & -2.16 \\
$C R[\%] \quad C R_{\text {tot }}[\%]$ & 0.145 & 0.149 & -2.46 \\
$C R_{\text {tot }}[\%]$ & 5.417 & 5.481 & -1.19 \\
$G_{\text {cool }}\left[\mathrm{kg} / \mathrm{m}^{2} \mathrm{~s}\right]$ & 14.4349 & 14.7485 & -2.17 \\
\hline \hline
\end{tabular}

Table 3: $\quad$ Percent error 
The lowest percent error occurs on wall thickness (fig. 29-30), the highest on coolant ratio (fig 31-32).

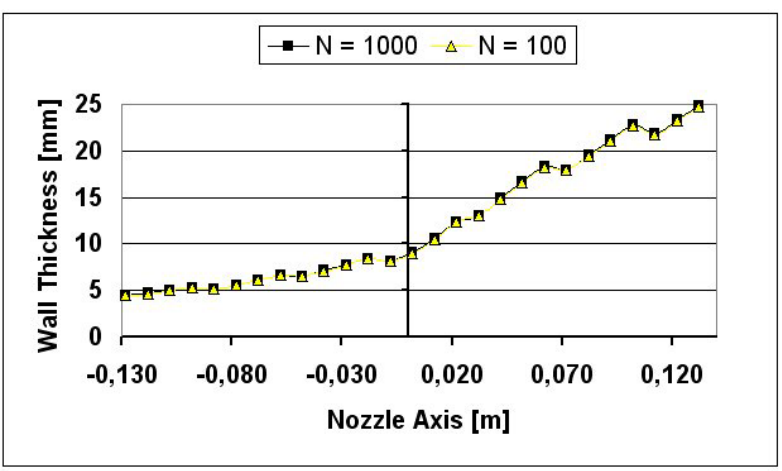

Fig. 29 Wall Thickness with different grids
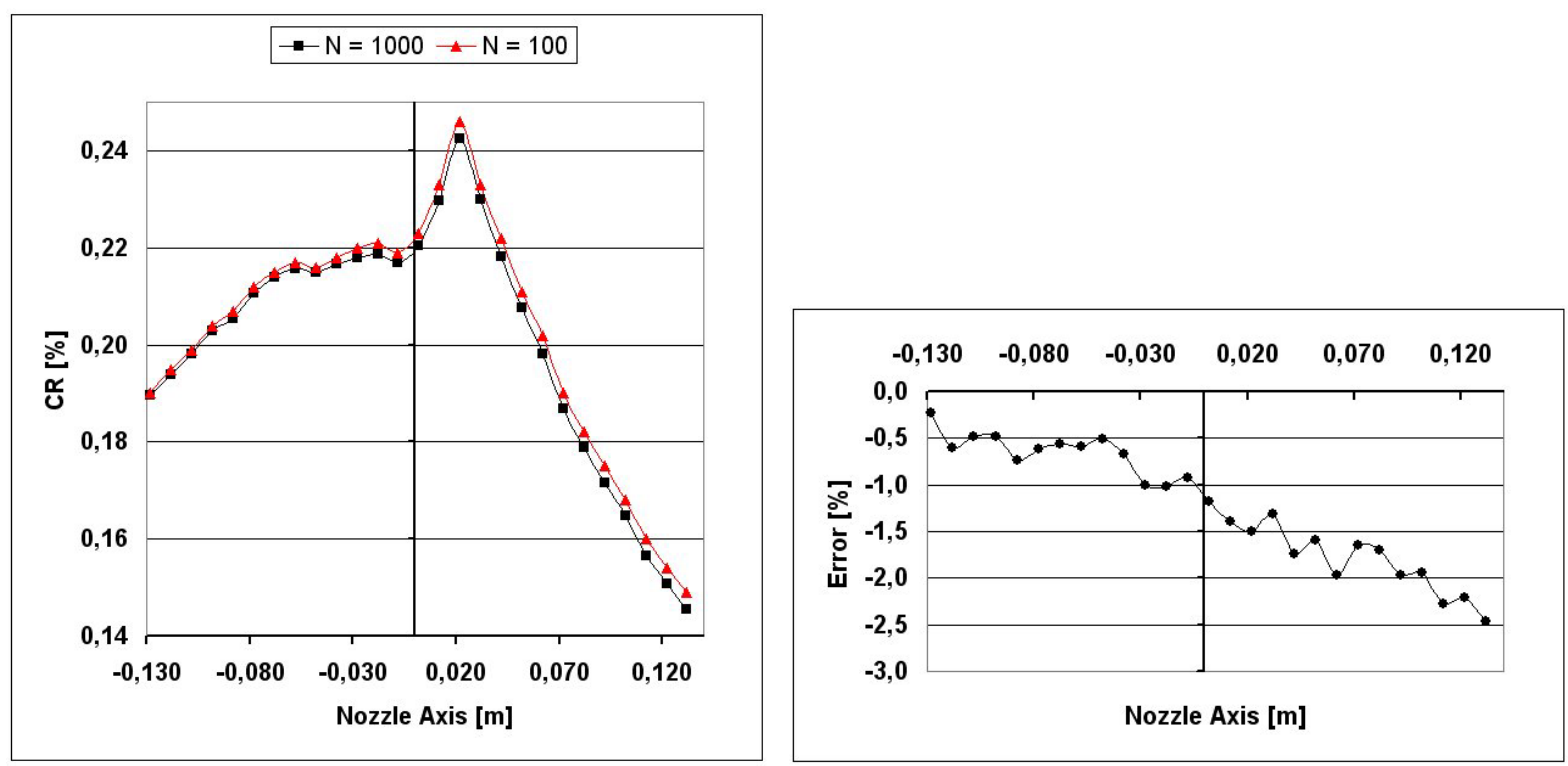

Fig. 31 Coolant Ratio with different grids

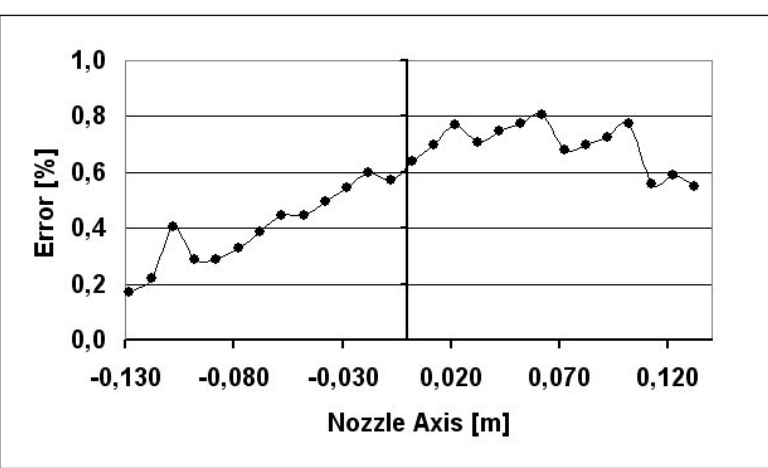

Fig. 30 Wall Thickness: percent error 


\section{REFERENCES}

${ }^{1}$ Quentmeyer, R. J., "Rocket Combustion Chamber Life-Enhancing Design Concepts," AIAA Paper 90-2116, July 1990.

2 Popp, M., Schmidt, G., "Rocket Engine Combustion Chamber Design Concepts for Enhanced Life,” AIAA Paper 96-3303, July 1996.

${ }^{3}$ Bucchi, A., Congiunti, A., Bruno, C., "Investigation of Transpiration Cooling Performance in LOX/Methane Liquid Rocket Engines," 54th International Astronautical Congress, Paper IAC-03-S.3.08, Sept. 2003.

${ }^{4}$ Congiunti, A., Bruno, C., Giacomazzi, E., “Supercritical Combustion Properties,” AIAA Paper 2003-478, Jan. 2003.

${ }^{5}$ Mulready, D., Advanced Engine Development at Pratt \& Whitney (The Inside Story of Eight Special Projects, 1946 - 1971), SAE International, Warrendale, 2001, pp. 87-101

${ }^{6}$ Sutton, G. P., Rocket Propulsion Elements (An introduction to the Engineering of Rockets), 6th ed., John Wiley \& Sons, New York, 1992, pp. 89-99

${ }^{7}$ Hill, P. G., Peterson, C. R., Mechanics and Thermodynamics of Propulsion, 2nd ed., Addison-Wesley Publishing Company, New York, 1992, pp. 541-551 
${ }^{8}$ Glass, D. E., Dilley, A. D., Kelly, H. N., "Numerical Analysis of Convection/Transpiration Cooling," NASA TM-1999-209828, Dec. 1999.

${ }^{9}$ Bear, J., Dynamics of Fluids in Porous Media, 1st ed., Dover Publications, New York, 1988, pp. 119-135.

${ }^{10}$ Landis, J. A., "Numerical Study of a Transpiration Cooled Rocket Nozzle", MS Thesis, AFIT/GA/ENY/95D-01. School of Engineering, Air Force Institute of Technology (AU), Wright-Patterson AFB, Dec. 1995.

11 Landis, J. A., Bowman, W. J., "Numerical Study of a Transpiration Cooled Rocket Nozzle," AIAA Paper 96-2580, July 1996.

${ }^{12}$ Serbest, E., Haidn, O. J., Meinert, J., Huhn, J., "Investigation on the Effect of Foreign Gas Transpiration on a Turbulent Boundary Layer,” AIAA Paper 2000-3386, July 2000.

13 Congiunti, A., Ierardo, N., Cuoco, F., Bruno, C., "High Pressure Methane Cooling Potential," 23rd International Space Technology and Science Conference, Matsue, Japan, Paper ISTS 2002-a-29, May 2002.

${ }^{14}$ Liang, K., Yang, B., Zhang, Z., "Investigation of Heat Transfer and Coking Characteristics of Hydrocarbon Fuels," Journal of Propulsion and Power, Vol. 14, No. 5, 1998, pp.789-796 .

${ }^{15}$ Hald, H., Ortelt, M., Fischer, I., Greuel, D., "CMC Rocket Combustion Chamber with Effusion Cooling," 54th International Astronautical Congress, Paper IAC-03-S.P.22, Sept. 2003. 